\title{
Application of stand density indices for Chinese fir (Cunninghamia lanceolata (Lamb.) Hook) plantation management
}

\author{
Lele $\mathrm{Lu}^{1,2, a}$, Bin Zhang, ${ }^{3, a}$, Jianguo Zhang ${ }^{1}$, Aiguo Duan ${ }^{1}$ and \\ Xiongqing Zhang ${ }^{1,2^{*}}$
}

\begin{abstract}
Lu, L., Zhang, B., Zhang, J., Duan, A., Zhang, X. 2018. Application of stand density indices for Chinese fir (Cunninghamia lanceolata (Lamb.) Hook) plantation management. - Forestry Studies | Metsanduslikud Uurimused 68, 51-63. ISSN 1406-9954. Journal homepage: http:/ / mi.emu.ee/forestry.studies
\end{abstract}

\begin{abstract}
The most important issues in Chinese fir (Cunninghamia lanceolata (Lamb.) Hook) management are the quantitative determination of stand density and the selection of appropriate density. Different stand density index models have advantages for special tree species, and this study aimed to estimate the carrying capacity of planted stands of Chinese fir and to select simple and reliable stand density indexes. Based on special experiment of different initial density, the maximum carrying capacity was estimated using Reineke's self-thinning rule, Nilson's sparsity theory, Beekhuis's relative-spacing hypothesis, Zhang's nutrientcompetition rule, Curtis's maximum stand basal area and Hui's crowding degree based on mean tree distance. The restricted maximum likelihood method (REML) implemented with 'nlme' package in R software was used to refine the parameters of thinning age in Richard's growth model. The results showed that stand density index models can describe the trends of stand density in response to tree growth: the higher the plantation initial density, the earlier age and stronger self-thinning capacity of stands. Reineke's SDI and Zhang's Z model are the most stable and suitable to estimate changes in the density of Chinese fir plantations, competition intensification, and the thinning age. The RD model can also be used, except at low Chinese fir densities. K, which can be affected by the mean crown width of trees, directly reflects the forest area of photosynthesis; this index is easy and simple to apply, but more research is needed to optimize the equation to evaluate whether a forest requires management and to determine the appropriate time for the first thinning and its intensity.
\end{abstract}

Key words: stand density index, stand sparsity, relative spacing, ratio of dominant height to nutrient area, relative density index, stand crowding degree.

\begin{abstract}
Authors' addresses: ${ }^{1}$ Key Laboratory of Tree Breeding and Cultivation of the State Forestry Administration, Research Institute of Forestry, Chinese Academy of Forestry, Beijing, 100091, P.R. China; ${ }^{2}$ Collaborative Innovation Center of Sustainable Forestry in Southern China, Nanjing Forestry University, Nanjing, 210037, P. R. China; ${ }^{3}$ College of Forestry, Central South University of Forestry and Technology, Changsha, Hunan 410004, P.R. China; ${ }^{\text {athe }}$ two authors contributed equally to this work; "e-mail: xqzhang85@caf.ac.cn
\end{abstract}

\section{Introduction}

Chinese fir (Cunninghamia lanceolata (Lamb.) Hook) is a very important timber tree species (Zhang et al., 2013). In order to satisfy the increase of timber demand, more silvicultural practices and long-term silvicultural trials are needed. In Chinese fir plantations, the spatial distribution of trees and relative density have a strong influence on tree height, diameter at breast height
(DBH), stand basal area and the use of nutrients and space (Nagaike et al., 1999; Sun et al., 2007). Therefore, in the management of Chinese fir, it is necessary to determine how tree height, $\mathrm{DBH}$, and stand density vary and to investigate the maximum density of stands at different sites and initial densities. Multi-level linear models can simulate individual-tree diameter growth (Zhao et al., 2013; Ma, 2015; Ma et al., 2015), and the initial density will influence self- 
pruning and nutrient competition (Sun et al., 2014; Dong et al., 2016).

Although Chinese fir management lags behind that of spruce (Picea sp.), radiata pine (Pinus radiata D.Don)and other major timber species in Europe (Xue et al., 2015; Xiang et al., 2015), sustainable forestry, as a paradigm of forest management, has proven that forest simulation is the best tool for forest management (Peng \& Wen, 2006). Stand density can be regarded as the most important factor that affects the carrying capacity, growth rate, wood quality and forest ecological functions (Meng, 1996). Therefore, stand density can also be used as an important feature in the evaluation of forest quality. In a fully stocked forest, stand density depends on the biological environment (e.g., solar radiation, nutrient level, resource and sink functions) (Durham, 1991; Harms et al., 1994), the physical environment (e.g., crown width, growing space), tree species, and age composition (Amateis \& Burkhart, 2012; Yang \& Burkhart, 2017). In Chinese fir plantation management, site index (SI) based on standard age $=20$ depends on the stand density, and the carrying capacity depends on the stand density and site index. Therefore, stand density can be estimated using maximum size-density relationships (MSDRs) (Sun et al., 1999; Gu et al., 2001; Mitsuda et al., 2003).

In a fully stocked forest, the MSDR is the maximum "trade-off" between the average tree size and number of trees per unit area that can be supplied in a given stand (Arisman et al., 2004; Arisman et al., 2005; Inoue, 2009; Kurinobu \& Miyaura, 2011). Measurements of MSDR have been carried out using different size variables, such as quadratic mean diameter (Reineke, 1933), relative space (Daniels \& Burkhart, 1988), nutrient area (Zhang et al., 2011b), and stand crowding degree (Hui et al., 2016). By comparing all MSDR measures with different size variables, Burkhart (2013) argued that quadratic mean diameter was the most informative in theory if the differences among tree size variables were not large. Zhang et al. (2011a) indicated that the ratio of dominant height $\left(\mathrm{H}_{\mathrm{d}}\right)$ to nutrient area and the forest mean crown width reflect the density. Hierarchical Bayesian models are a useful method to predict the MSDR line (Cui et al., 2016). Stand density models, i.e., Reineke's stand density index (SDI), Nilson's stand sparsity density (SD), Beekhuis's relative spacing (RS), Zhang's ratio of dominant height to nutrient area $(Z)$, Curtis's relative density index (RD), and Hui's stand crowding degree (K), were compared and evaluated in this study.

\section{Material and Methods}

Data used in this study were from Chinese fir stands established using seedlings that were bare-root planted in 1982 at Weimin farm in Fujian, south of China. This region has a subtropical monsoon climate with an annual average temperature of $17.7^{\circ} \mathrm{C}$, average annual air relative humidity of $82 \%$, sunshine duration of $1,740.7 \mathrm{~h}$, a frost-free period of $270 \mathrm{~d}$, and rainfall of $1,768 \mathrm{~mm}$.

A total of 15 plots were planted in a randomized block arrangement with the following five densities (treatments): A $(2 \mathrm{~m} \times 3 \mathrm{~m}, 1,667$ trees / ha), B $(2 \mathrm{~m} \times 1.5 \mathrm{~m}$, 3,333 trees / ha), C ( $2 \mathrm{~m} \times 1 \mathrm{~m}, 5,000$ trees / ha), $\mathrm{D}(1 \mathrm{~m} \times 1.5 \mathrm{~m}, 6,667$ trees / ha) and $\mathrm{E}$ $(1 \mathrm{~m} \times 1 \mathrm{~m}, 10,000$ trees / ha). Each treatment was replicated three times. Each plot was 0.06 ha in size and a buffer zone consisting of two lines of similarly treated trees surrounded each plot.

Diameter at breast height (DBH) was measured annually for ages 3-28. In addition, mean crown width (CW) and height to crown base were measured from the $4^{\text {th }}$ year; tree height $(\mathrm{H})$ was recorded annually for ages 1-28; each tree was measured annually for ages 1-10; and $\mathrm{H}, \mathrm{H}_{\mathrm{d}}$, and CW of every $5^{\text {th }}$ trees were measured biennially for ages 12-28. The descriptions of each plot are presented in Table 1. 
Table 1. Descriptions of plots.

\begin{tabular}{|c|c|c|c|c|c|c|c|c|c|c|c|c|}
\hline \multirow{2}{*}{ Plot } & \multirow{2}{*}{$\begin{array}{l}\text { Site } \\
\text { Index } \\
(\mathrm{m})\end{array}$} & \multirow{2}{*}{$\begin{array}{c}\text { Initial } \\
\text { density* } \\
\text { (Trees/ha) }\end{array}$} & \multicolumn{3}{|c|}{ Height* $(m)$} & \multirow{2}{*}{$\begin{array}{c}\text { Stand } \\
\text { density** } \\
\text { (Trees/ha) }\end{array}$} & \multicolumn{3}{|c|}{ Height** (m) } & \multicolumn{3}{|c|}{$\mathrm{DBH}^{* *}(\mathrm{~cm})$} \\
\hline & & & Min. & Max. & Mean & & Min. & Max. & Mean & Min. & Max. & Mean \\
\hline $\mathrm{A} 1$ & 16 & 1,667 & 0.39 & 0.99 & 0.61 & 1,650 & 6.60 & 23.10 & 17.11 & 7.20 & 32.80 & 20.33 \\
\hline A2 & 20 & 1,667 & 0.26 & 0.89 & 0.53 & 1,567 & 8.20 & 26.90 & 20.51 & 7.30 & 33.30 & 22.60 \\
\hline A3 & 22 & 1,667 & 0.35 & 0.89 & 0.57 & 1,467 & 15.00 & 28.00 & 22.71 & 12.80 & 36.10 & 24.63 \\
\hline B1 & 14 & 3,333 & 0.27 & 69.00 & 0.91 & 3,250 & 4.50 & 21.20 & 15.43 & 4.30 & 26.30 & 16.14 \\
\hline B2 & 20 & 3,333 & 0.24 & 0.88 & 0.52 & 1,683 & 12.90 & 28.30 & 20.77 & 9.70 & 32.60 & 20.35 \\
\hline B3 & 18 & 3,333 & 0.21 & 0.89 & 0.55 & 2,150 & 9.60 & 28.30 & 19.60 & 2.00 & 41.30 & 18.98 \\
\hline $\mathrm{C} 1$ & 16 & 5,000 & 0.22 & 1.57 & 0.60 & 3,900 & 8.80 & 42.90 & 16.45 & 3.60 & 29.20 & 15.23 \\
\hline C2 & 22 & 5,000 & 0.18 & 1.46 & 0.58 & 2,617 & 11.30 & 113.60 & 18.90 & 8.80 & 33.70 & 17.28 \\
\hline C3 & 18 & 5,000 & 0.12 & 0.88 & 0.54 & 1,700 & 13.90 & 28.20 & 20.39 & 10.40 & 28.70 & 22.10 \\
\hline D1 & 14 & 6,667 & 0.19 & 1.00 & 0.60 & 4,183 & 9.80 & 25.20 & 16.59 & 5.70 & 31.00 & 14.79 \\
\hline D2 & 20 & 6,667 & 0.20 & 0.93 & 0.57 & 3,050 & 10.70 & 25.50 & 18.99 & 7.40 & 34.00 & 17.43 \\
\hline D3 & 14 & 6,667 & 0.22 & 0.87 & 0.51 & 1,683 & 13.10 & 24.40 & 19.50 & 11.40 & 31.10 & 19.67 \\
\hline E1 & 14 & 10,000 & 0.12 & 0.97 & 0.57 & 3,167 & 8.30 & 25.70 & 16.05 & 6.20 & 33.00 & 14.69 \\
\hline E2 & 20 & 10,000 & 0.25 & 6.00 & 0.58 & 1,667 & 11.40 & 28.70 & 20.30 & 7.90 & 36.10 & 19.80 \\
\hline E3 & 12 & 10,000 & 0.19 & 1.00 & 0.57 & 3,150 & 8.40 & 27.00 & 16.33 & 2.80 & 34.10 & 15.07 \\
\hline
\end{tabular}

Note: * measured in $1982 ;{ }^{* *}$ measured in 2010.

Six different stand density index models were selected to measure the changes of stand density. In Reineke's self-thinning rule (Reineke, 1933), the maximum stand density $(\mathrm{N})$ and quadratic mean diameter $\left(D_{q}\right)$ in fully stocked even-aged stands have a linear relationship on a log-log scale; the equation is:

$\mathrm{LnN}=\mathrm{a}+\mathrm{b} \times \mathrm{LnD}_{\mathrm{q}}$

where $a$ and $b$ are the equation coefficients.

Reineke defined a stand density index (SDI) to estimate the carrying capacity in even-aged stands. According to Reineke's theory, SDI is expressed in the form

$\mathrm{SDI}=\mathrm{N}\left(\frac{\mathrm{D}_{\mathrm{q}}}{\mathrm{D}_{0}}\right)^{\mathrm{b}}$

where the metric unit is number of trees per ha $(\mathrm{N}), \mathrm{cm}\left(\mathrm{D}_{\mathrm{q}}\right.$ and $\left.\mathrm{D}_{0}\right)$. SDI describes the density of stands with $\mathrm{D}_{\mathrm{q}}$ and $\mathrm{N}$ by calculating the number of stems per hectare in these stands at 10 inches index diame- ter $(25.4 \mathrm{~cm})$. In China, an index diameter $\mathrm{D}_{0}=20 \mathrm{~cm}$ is used. Coefficient $\mathrm{b}$, which was previously defined, is the self-thinning ratio.

Nilson proposed the 'sparsity index' model, using the number of trees and quadratic mean diameter of a stand (Nilson, 2006). In this model, stand sparsity (L) and quadratic mean diameter $\left(\mathrm{D}_{\mathrm{q}}\right)$ are linearly related, that is,

$\mathrm{L}=\sqrt{\frac{10000}{\mathrm{~N}}}$ and

$\mathrm{D}_{\mathrm{q}}=\mathrm{a}_{2}+\mathrm{b}_{2} \mathrm{~L}=\mathrm{a}_{2}+100 \mathrm{~b}_{2} \mathrm{~N}^{-1 / 2}$

where $\mathrm{a}$ and $\mathrm{b}$ are coefficients. The model of Nilson's self-thinning model follows:

$N=a\left(\frac{D_{0}+k}{D_{q}+k}\right)^{2}$

where $\mathrm{a}=100 \mathrm{~b}_{2} /\left(\mathrm{D}_{0}-\mathrm{a}_{2}\right)^{2}$, and $\mathrm{k}=-\mathrm{a}_{2}$ are constant parameters of a given tree speices in a given region. According to Nilson's model of self-thinning, Nilson's stand 
sparsity density (SD) can be described as (Zeide, 2010):

$\mathrm{SD}=\mathrm{N}\left(\frac{\mathrm{D}_{\mathrm{q}}+\mathrm{k}}{\mathrm{D}_{0}+\mathrm{k}}\right)^{2}$

In Beekhuis's relative spacing (RS) equation (Beekhuis, 1965), the relative spacing value depends on the dominant tree height and the number of trees per ha, which cannot be reflected by stand site quality, diameter at breast height, and so on.

$\mathrm{RS}=\frac{100}{\mathrm{~N}^{1 / 2} \times \mathrm{H}_{0}}=\sqrt{\frac{10000}{\mathrm{~N} \times \mathrm{H}_{0}^{2}}}$

$\mathrm{H}_{0}$ is the dominant tree height of the stand (m).

Zhang et al. (2011a) focused on variation in Reineke's self-thinning ratio between different species. These authors defined nutrient area with the reciprocal of relative spacing, and the ratio of dominant height to nutrient area as a new density index (Z). $\mathrm{Z}$ is described as

$\mathrm{Z}=\frac{\mathrm{N} \times \mathrm{H}_{0}}{10000}$

In forest management, the higher the plant density, the sooner the stand density is stable. Compared to Reineke's SDI, the Z index can be used across a wide age for plantation management. The $\mathrm{Z}$ index is a nonparametric density index, which increases with increasing planting density.

Similar to Reineke's SDI equation, when the stand is fully stocked, the stand has maximum stand basal area $\left(\mathrm{G}_{\mathrm{L}}\right)$. Curtis used the ratio of observed stand basal area $\left(G_{o b s}\right)$ to $G_{L}$ to calculate the change in stand basal area. Curtis's relative density index (RD) is expressed in the following form (Curtis, 2010),

$R D=\frac{G_{o b s}}{G_{L}}=\frac{G_{o b s}}{k\left(D_{q}^{b}\right)}$,

where $\mathrm{k}$ and $\mathrm{b}$ are coefficients, and $\mathrm{b}=$ $2-\beta$ ( $b$ is the stand thinning ratio, $\beta$ is the self-thinning ratio). Since $\mathrm{k}$ is a constant multiplier, Curtis replaced k with 1.0; the value of RD and the relative rank of a stand remain unchanged, so the equation can be expressed as

$R D=\frac{G_{o b s}}{D_{q}^{b}}$

Hui et al. (2016) proposed a new index K (stand crowding degree) based on the forest mean crown width of trees (CW) and the mean tree distance $(\mathrm{L})$. The reasonable interval of the $\mathrm{K}$ value ranges from 0.9 to 1.1; this index can be used to evaluate whether the forest requires management and to determine the appropriate time for the first thinning and its management intensity. If $\mathrm{K}>1.1$, this mean the forest density is low, and without thinning, if the $\mathrm{K}$ value is too high, the stand will need to be replanted. If $K<0.9$, the stand needs to be thinned to reduce the crowding degree. The equation used to determine the stand crowding degree index, $\mathrm{K}$, is

$\mathrm{K}=\frac{\mathrm{L}}{\mathrm{CW}}=\frac{\sqrt{10000 / \mathrm{N}}}{\mathrm{CW}}$

where $\mathrm{L}$ is the average tree distance $(\mathrm{m})$, and $\mathrm{CW}$ is the average stand crown width (m).

The changes in stand density index models, increasing with age (the crowding degree curve uses the $1 / \mathrm{K}$ - age relationship line), shown as an S-curve. Richards' equation is a widely used model for modelling the S-curve, which can be expressed as follows:

$y=a\left(1-e^{-b \times t}\right)$

where y denotes stand density index (e.g., $\mathrm{SDI}, \mathrm{SD}, \mathrm{RS}, \mathrm{RD}, \mathrm{Z}, \mathrm{K})$, $\mathrm{t}$ is stand age, and $\mathrm{a}$, $b$, and $c$ are equation coefficients.

In this study, a plot-level random-effects parameter was added to parameter $a$ of the stand density index model. The randomeffect parameter was defined as: $\mathrm{u} \sim \mathrm{N}(0$, $\mathrm{v})$, where $\mathrm{v}$ is the variance. All parameter 
vectors can be estimated through the optimization of the likelihood function, that is, by applying the restricted maximum likelihood method (REML). The unstructured covariance structure was used for describing the variance-covariance structure of random effects. Parameter estimation was implemented with 'nlme' package in R software (Pinheiro et al., 2017).

In the Richards equation, the age at the inflection point $\left(t_{r}\right.$, equation 12) indicates that competition between trees has intensified, and the age where the increasing rate of the equation slows ( $t_{\mathrm{m}}$, equation 13) indicates that competition has approached a steady state.

$\mathrm{t}_{\mathrm{r}}=\frac{\ln \mathrm{c}}{\mathrm{b}}$

$t_{m}=-\frac{\ln \frac{3 c-1-\sqrt{5 c^{2}-6 c+1}}{2 c^{2}}}{b}$

\section{Results and Discussion}

Reineke's self-thinning rules were used to measure the relative density, and fully stock stands with relative density greater than or equal to 0.7 were reported (Das \& Singh, 2016, Ramananantoandro et al., 2016; Dehane et al., 2017). Tree growth increased the competition for resources such as solar radiation, water, and nutrients. Higher plantation density improved the competition and resulted in earlier full stocking and self-thinning age of stands. An estimate of relative density was obtained from $\mathrm{N} / \mathrm{N}_{\max }$ $\left(\mathrm{N}_{\max }\right.$ : the maximum density under the selfthinning rule) in each stand; plot $E$ with the highest density of $1 \times 1 \mathrm{~m}$ was fully stocked at the $8^{\text {th }}$ year, plots $C$ and $D$ at age 10 , and the stand with the lowest plantation density reached full stocking by age 14 . At the age of 28 , as density increased, the relative density decreased from 0.94 to 0.27 . Reineke (1933) reported that in fully stocked stands and even-aged forestry, the self-thinning rate is approximately 1.605; in this study, as the plantation density decreased from $2 \times 3 \mathrm{~m}$ to $1 \times 1 \mathrm{~m}$, the self-thinning rate increased to $0.282,1.213,1.468,1.406$ and 1.507 , and rate equaled 1.821 without considering the plantation density.

Site quality is considered as the capacity of nutrients, water and other resources to support tree growth. Nutto et al. (2007) used stand dominant height at base age as a site index to represent site quality. At the same plantation density, trees growth faster at a higher site index (Figure 1). If trees in stands are strongly crowded, plantation density determines the self-thinning rate and the survival rate rather than site quality (Figure 1 plot E).

Hui et al. (2016) reported that after site quality, stand density is the second most important factor that influences stand growth, the carrying capacity, and forest quality and stand stability. Different stand density index models have different advantages to describe the stage of survival during the competition process throughout forest formation and development. Figure 2 shows that during the earlier periods of stand growth, as stand age increases, the stand density index models SDI, SD, Z and RD increased, and the change became steady or declined slightly during the later stage. This is consistent with stand development and the principles of stand density index models, such as SDI, SD, Z, and $\mathrm{RD}$, i.e., the greater the density index, the more crowed the forest. The changes in RS among different initial density values decreased with stand growth and became steady at later forest ages, which is in line with the following: the smaller the RS, the more crowded the forest. When we use a density index to measure stand crowding, the best density index model can reflect the degree of tree crowding as well as distinguish between different initial densities. From the 10th year, RS differs little between different plantation densities (Figure 2); consequently, this density index is not suitable to assess the degree of tree crowding. 

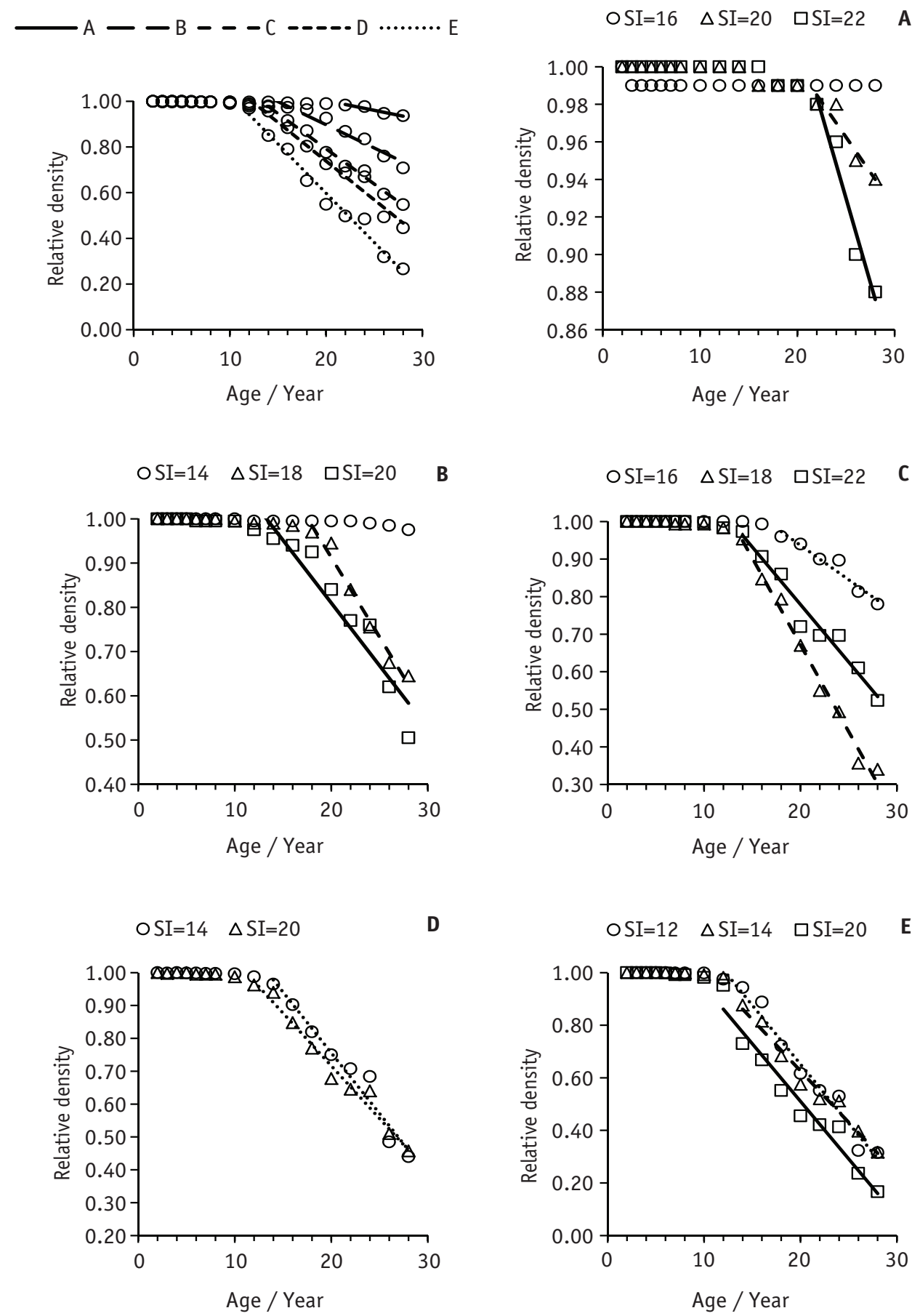

Figure 1. Relationship between relative density and planting density across different site index values. 
$O A \Delta B \quad \square C \diamond D \times E$

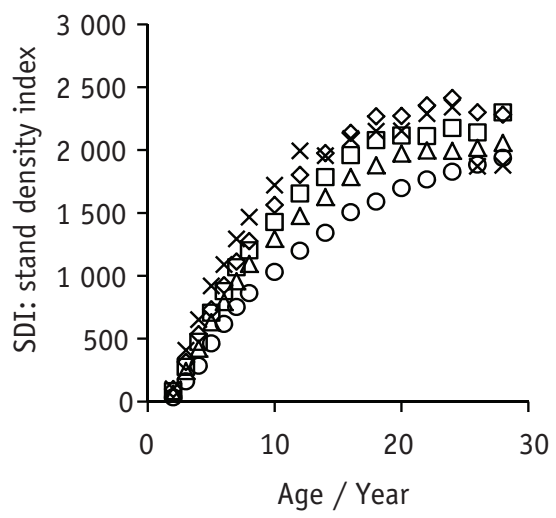

$O A \Delta B \square C \diamond D \times E$

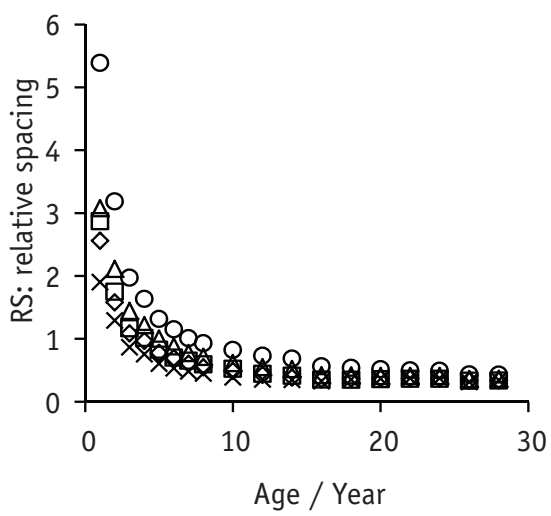

$O A \triangle B \quad \square \diamond D \times E$

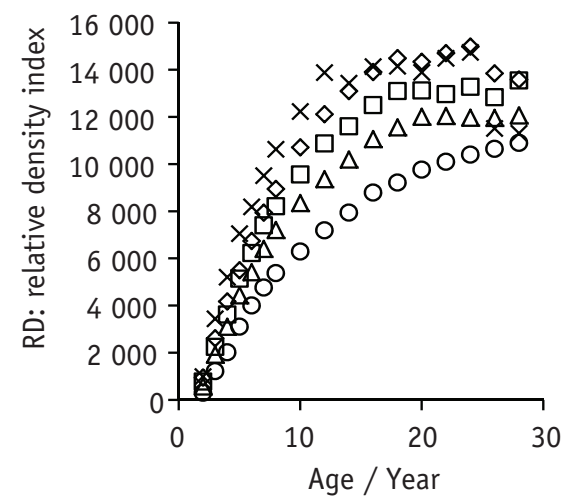

$O A \triangle B \quad C \diamond D \times E$

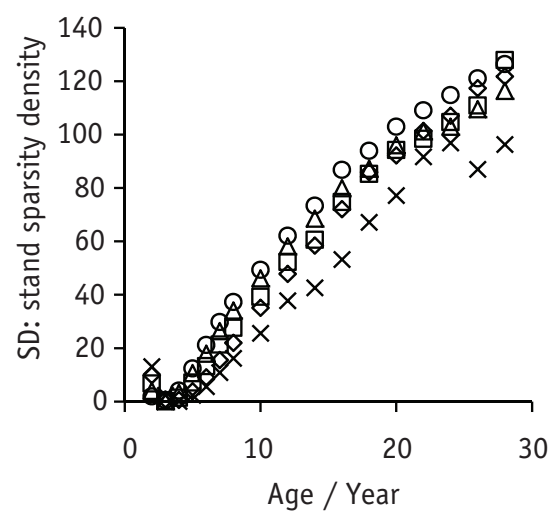

$O A \triangle B \quad \square C \diamond D \times E$

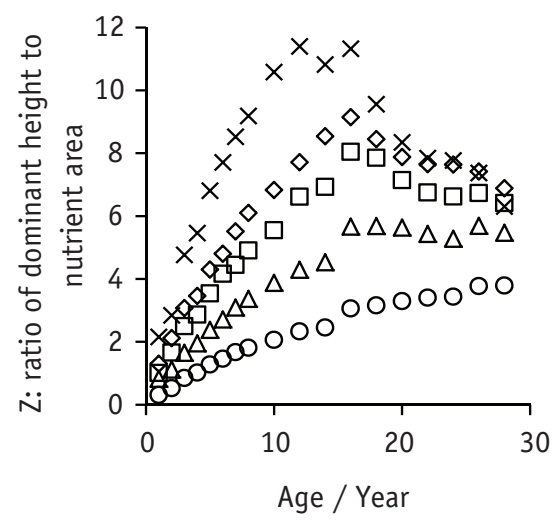

$O A \triangle B \square C \diamond D \times E$

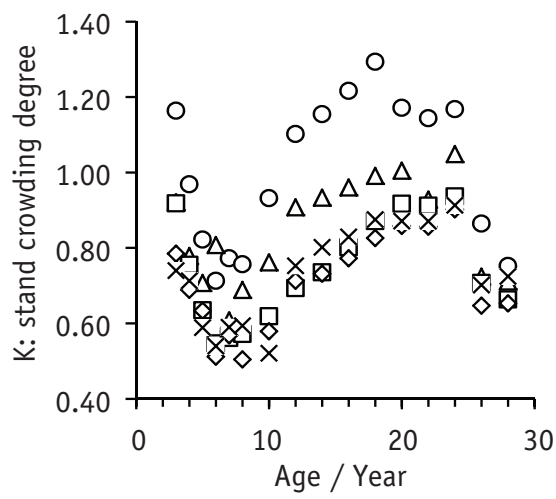

Figure 2. Relationship between stand age and stand density index models for different planting densities. 
A similar result was obtained in the study of Zhang (2011b) with respect to the first thinning age of a Pinus massoniana Lamb. plantation.

Changes in K decreased initially and then increased with forest growth. Stands with a higher initial density were the first to reach the lowest point of $\mathrm{K}$; this indicates that higher plantation density and crowding can increase stand competition. Figure 2 shows that in plot B from 3-12 years and in stands with density C, D, and E from 3-28 years, the value of $K$ was less than 0.9 (except in plot $C$, where the value was slightly higher than 0.9 at 20-24 a). By contrast, the $\mathrm{K}$ of plot A was higher than 0.9 for almost the whole growth period and was even higher than 1.1 from 14-24 a. Li (2012) reported that the stand crowding degree $(\mathrm{K})$ can even be used in studies of natural forest management.

The values from these density index models (SDI, SD, RD and Z) increase with forest growth. In order to distinguish these indexes, it is necessary to establish relationship equations between stand age and density indexes.

The results (Table 2) shows that, except for density index model SD, as plantation density increased, $t_{r}$ and $t_{m}$, two important characteristic parameters, decreased, which indicates that at high stand density, competition and self-thinning occur earlier. This is consistent with the process of stand growth, and the density index model SD is not suitable for explaining the growth of Chinese fir plantations. According to Hui's definition of $\mathrm{K}$ and the results presented in Figure 2 , the changes of $1 / \mathrm{K}$ between the $3^{\text {rd }}-10^{\text {th }}$ year conform to Richard's equation, and the value of $t_{r}$ is 1.5-2.2, and that of $t m$ is 2.4-3.2. These values are obviously lower than those of SDI, Z and RD, especially when thinning starts at 2.0-2.6 years old; this result does not conform to Chinese fir plantation management, so the stand density index of $\mathrm{K}$ is not suitable.

A smaller value of $t_{m}$ indicates the density index has high sensitivity, and the mean values of $t_{r}$ and $t_{m}$ are usually used as the beginning age of stand thinning. In addition, SDI depends on tree species, site quality, fully stocked status, and the selection of $\mathrm{D}_{\mathrm{q}}$, therefore, $\mathrm{RD}$ is more simple than SDI for application in forest management.

A comparison of the values of SDI, Z and RD with the observed values using a paired samples $\mathrm{T}$ test indicated that the differences between observed values and the SDI model were not significant (0.0590.604 ), and the correlation coefficient ranged from 0.985-0.999 (Table 3). The same trend of model $\mathrm{Z}$ was observed, with a difference of $0.270-0.984$, and correlation of $0.801-$ 0.987 . RD is another excellent model, except for the higher initial density of E: significant differences (0.010) and a lower correlation (0.251) were observed.

Table 2. $\quad$ tr and tm of different stand density index models for different initial density values.

\begin{tabular}{|c|c|c|c|c|c|c|c|c|c|c|c|c|c|c|c|}
\hline \multirow{2}{*}{$\begin{array}{l}\text { Initial } \\
\text { density }\end{array}$} & \multicolumn{3}{|c|}{ SDI } & \multicolumn{3}{|c|}{ SD } & \multicolumn{3}{|c|}{ Z } & \multicolumn{3}{|c|}{ RD } & \multicolumn{3}{|c|}{ K } \\
\hline & $\operatorname{tr}$ & $\mathrm{tm}$ & mean & $\operatorname{tr}$ & $\mathrm{tm}$ & mean & tr & $\mathrm{tm}$ & mean & $\operatorname{tr}$ & $\mathrm{tm}$ & mean & $\operatorname{tr}$ & $\mathrm{tm}$ & mean \\
\hline A & 5.3 & 10.7 & 8.0 & 8.5 & 15.2 & 11.9 & 3.5 & 5.8 & 4.7 & 4.5 & 9.4 & 7.0 & 2.2 & 3.0 & 2.6 \\
\hline B & 4.7 & 8.8 & 6.8 & 8.4 & 14.1 & 11.2 & 1.7 & 5.1 & 3.4 & 4.1 & 7.3 & 5.7 & 1.7 & 2.5 & 2.1 \\
\hline C & 4.6 & 8.4 & 6.5 & 9.8 & 16.6 & 13.2 & 2.2 & 5.0 & 3.6 & 4.1 & 7.3 & 5.7 & 2.2 & 3.2 & 2.7 \\
\hline D & 4.8 & 8.5 & 6.7 & 10.8 & 17.0 & 13.9 & 2.1 & 4.7 & 3.4 & 4.1 & 7.4 & 5.8 & 1.8 & 2.8 & 2.3 \\
\hline $\mathrm{E}$ & 4.0 & 6.8 & 5.4 & 11.7 & 17.9 & 14.8 & 2.1 & 3.6 & 2.9 & 3.5 & 5.8 & 4.7 & 1.5 & 2.4 & 2.0 \\
\hline
\end{tabular}

Note: SDI, stand density index; SD, stand sparsity density; $Z$, ratio of dominant height to nutrient area; $R D$, relative density index; $K$, stand crowding degree. 
In order to optimize the stand density index, explain the process of stand density change and reduce the influence of uncertainty, the NLME method with the R software was used to fit the density model (Table 4). The correlation coefficients showed that the SDI, SD and RD models had the highest fitting degree (0.9044-0.9935), and the model $\mathrm{Z}$ showed the worst performance at the lowest and highest initial densities of the A and E plots $\left(\mathrm{R}^{2}=0.0000\right.$ 0.0700). The $1 / \mathrm{K}$ model did not exhibit a good fitting effect under different initial densities $\left(R^{2}=0.1354-0.7328\right)$. The parameters a, $\mathrm{b}$ and $\mathrm{c}$ of the SDI and RD models showed an increasing trend with increasing initial density, which accorded with the definitions of the parameters. The relationship between the parameters of models SD and $\mathrm{Z}$ and the initial planting density remains uncertain. The performance of these two models in the density management and regulation of Chi- nese fir plantation was worse than that of the SDI model and RD model.

According to the definition and changes in $\mathrm{K}$, a 1 / $\mathrm{K}$ value between $3-10$ years was used to calculate the coefficients of Richard's growth equation (Equation 11). When the stand age was $>10$ years, stand density decreased obviously, and the stand crowding degree increased. In addition, some of the trees died due to competition for light and nutrients, and tree survival depends on density (Zhang et al., 2009). According to the results of Hui's study, if the value of $\mathrm{K}$ is lower than 0.9 , the trees in a stand are crowded; the results in Figure 2 show that the $\mathrm{K}$ value of plots $\mathrm{B}-\mathrm{E}$ was lower than 0.9 from the beginning to age 28 years, which is consistent with the conclusion drawn from table 3 but different from the results of the RD and SDI models and the actual crown closure. However, based on the value of $\mathrm{R}^{2}$ (Table 4) using Richard's growth equation

Table 3. Paired samples T test of different models.

\begin{tabular}{rrrrrrrrr}
\hline & Initial & & & \multicolumn{3}{c}{$95 \%$ confidence interval } & & \\
Model & density & Mean & \multicolumn{1}{c}{ SD } & \multicolumn{1}{c}{ SE } & Lower & Higher & Sig. & $R^{2}$ \\
\hline SDI & A & -9.706 & 36.204 & 8.781 & -28.320 & 8.908 & 0.285 & 0.999 \\
& B & -18.177 & 35.139 & 8.523 & -36.244 & -0.109 & 0.059 & 0.999 \\
& C & 22.941 & 57.542 & 13.956 & -6.644 & 52.526 & 0.120 & 0.998 \\
& D & 22.294 & 52.644 & 12.768 & -4.773 & 49.361 & 0.100 & 0.998 \\
& E & 15.706 & 122.413 & 29.689 & -47.233 & 78.645 & 0.604 & 0.985 \\
\hline Z & A & -2.284 & 0.941 & 0.228 & -2.767 & -1.800 & 0.270 & 0.895 \\
& B & 0.005 & 0.252 & 0.061 & -0.125 & 0.134 & 0.941 & 0.987 \\
& C & 0.011 & 0.511 & 0.124 & -0.252 & 0.274 & 0.930 & 0.965 \\
& D & 0.020 & 0.602 & 0.146 & -0.289 & 0.330 & 0.892 & 0.959 \\
& E & 0.007 & 1.419 & 0.344 & -0.723 & 0.737 & 0.984 & 0.801 \\
\hline RD & A & -45.497 & 217.626 & 52.782 & -157.390 & 66.396 & 0.401 & 0.998 \\
& B & -892.307 & 395.369 & 95.891 & -1095.587 & -689.027 & 0.074 & 0.996 \\
& C & 128.430 & 308.294 & 74.772 & -30.080 & 286.941 & 0.105 & 0.998 \\
& D & 134.078 & 419.077 & 101.641 & -81.392 & 349.547 & 0.206 & 0.996 \\
& E & 2788.701 & 3905.110 & 947.128 & 780.879 & 4796.523 & 0.010 & 0.251 \\
\hline
\end{tabular}

Note: SDI, stand density index; Z, ratio of dominant height to nutrient area; RD, relative density index. 
Table 4. Parameter estimation and $\mathrm{R}^{2}$ of density models.

\begin{tabular}{|c|c|c|c|c|c|}
\hline \multirow[b]{2}{*}{ Model } & \multirow{2}{*}{$\begin{array}{c}\text { Initial } \\
\text { density }\end{array}$} & \multicolumn{3}{|c|}{ Parameter } & \multirow[b]{2}{*}{$\mathrm{R}^{2}$} \\
\hline & & $\mathrm{a}$ & $b$ & c & \\
\hline \multirow[t]{5}{*}{ SDI } & $A$ & 2009.083 & 0.126 & 1.948 & 0.992 \\
\hline & B & 2071.422 & 0.181 & 2.363 & 0.992 \\
\hline & C & 2142.677 & 0.198 & 2.498 & 0.964 \\
\hline & D & 2318.751 & 0.204 & 2.649 & 0.977 \\
\hline & $\mathrm{E}$ & 2085.886 & 0.295 & 3.265 & 0.931 \\
\hline \multirow[t]{5}{*}{ SD } & A & 137.506 & 0.116 & 2.687 & 0.992 \\
\hline & B & 115.122 & 0.142 & 3.278 & 0.985 \\
\hline & C & 124.109 & 0.120 & 3.232 & 0.979 \\
\hline & D & 123.073 & 0.137 & 4.396 & 0.994 \\
\hline & E & 104.427 & 0.138 & 5.011 & 0.952 \\
\hline \multirow[t]{5}{*}{ Z } & A & 5.905 & 0.361 & 3.592 & 0.000 \\
\hline & B & 5.866 & 0.137 & 1.268 & 0.908 \\
\hline & C & 7.164 & 0.218 & 1.627 & 0.807 \\
\hline & D & 8.044 & 0.246 & 1.688 & 0.813 \\
\hline & $\mathrm{E}$ & 9.124 & 0.515 & 2.940 & 0.070 \\
\hline \multirow[t]{5}{*}{$\mathrm{RD}$} & A & 11107.907 & 0.136 & 1.850 & 0.992 \\
\hline & B & 12933.349 & 0.232 & 2.564 & 0.953 \\
\hline & C & 12933.349 & 0.232 & 2.564 & 0.953 \\
\hline & D & 14238.486 & 0.236 & 2.648 & 0.964 \\
\hline & $\mathrm{E}$ & 13365.905 & 0.361 & 3.592 & 0.904 \\
\hline \multirow[t]{5}{*}{$1 / K$} & A & 1.270 & 1.086 & 10.650 & 0.647 \\
\hline & B & 1.429 & 0.976 & 5.015 & 0.317 \\
\hline & C & 1.750 & 0.871 & 6.724 & 0.733 \\
\hline & D & 1.786 & 0.852 & 4.546 & 0.360 \\
\hline & E & 1.710 & 0.923 & 4.083 & 0.135 \\
\hline
\end{tabular}

Note: SDI, stand density index; SD, stand sparsity density; $Z$, ratio of dominant height to nutrient area; $R D$, relative density index; $K$, stand crowding degree. $A, 1,667$ trees/ha; $B, 3,333$ trees/ha; $C, 5,000$ trees/ ha; D, 6667 trees/ha; E, 10,000 trees/ha; a, b, c, equation coefficients; $R^{2}$, goodness of fit.

for ages 3-10 years, the accuracy of the $\mathrm{K}$ and $1 / \mathrm{K}$ models is lower than that of other models.

The value of RD was determined using the stand basal area and self-thinning ratio $(\beta)$; these two indicators are affected by the growth of trees, while light intensity can also affect Chinese fir (Cheng et al., 2011). Reineke's equation also uses a self-thinning ratio $(\beta)$ to calculate SDI and the maximum size density, such as in the management of Japanese cypress and red pine (Inoue et al., 2004), but another important coefficient $D_{q}$ has different standard values for different tree species, operation methods and objectives (Burkhart \& Tomé, 2012). The growth and self-thinning of Chinese fir plantations can be influenced by site quality (such as 
site index, climate factors) (Zhang et al., 2011; Charru et al., 2012; Brunet-Navarro et al., 2016). Therefore, when using the $\mathrm{R}$ procedure to estimate the parameters of Richards equation, the random effects of parameters $a$ and $b$ between plots affect the accuracy of model estimation. The random effects increased with increasing initial density. The $\mathrm{R}^{2}$ value of model $\mathrm{RD}$ ranged from 0.9044-0.9915 under different initial densities.

The stand crowing degree $(\mathrm{K})$ not only considers the relative space but can be used in natural forestry management, compared with RD and SDI, i.e., three different stand density models that do not consider the effect of site, climate, forest management and other factors.

Reineke (1933) stated that SDI was a stable index that cannot be influenced by site quality and initial density when stands are fully stocked. However, mortality models can be improved by selecting variables such as regional climate (Qiu et al., 2015), and site index plays an important role in self-thinning in Chinese fir plantations (Figure 1, Table 3). Therefore, in order to increase the accuracy of model prediction, whether climate factors and site index will be included in the self-thinning rule and Richards equation requires more research and reflection because more parameters will increase the complexity of models.

\section{Conclusions}

Our study evaluated approaches to estimate the stand carrying capacity of tree numbers per unit area in Chinese fir management and enhanced the understanding of competition and forest stand density dynamics. These results can provide information on plantation density, thinning schedules and thinning ratios.

As a classic stand density index model, SDI is also suitable for the management of Chinese fir plantations, but its self-thinning rate and $D_{q}$ need to be determined based on tree species and a considerable amount of data. According to Richard's growth equation, the first thinning age under the SDI model was calculated as 5.4 to 8.0 years, which is similar to actual Chinese fir management in China. RD can be regarded as the deformation of Reineke's SDI model; although the predicted thinning age is not significantly different from that of SDI, it is not suitable for management at higher initial density, and the self-thinning rate and $\mathrm{D}_{\mathrm{q}}$ also need to be calculated.

$\mathrm{Z}$ and $\mathrm{K}$, used as stand density indexes, have appeared in recent years. Compared with SDI and RD, Z is an excellent model with fewer statistics and easy measurements, and its predicted results of $t_{r}$ and $t_{m}$ are not significantly different from those of SDI. Although the results showed that K was not suitable, Hui provided a range of $K$ values $(0.9,1.1)$ for plantations and natural forest management. This index has few parameters that can be easily and accurately measured; therefore, its further optimization is worthwhile.

Acknowledgments. The authors express their appreciation to the Scientific and Technological Task in China (No. 2016YFD0600302-1), the National Natural Science Foundation of China (No. 31670634), and the Fundamental Research Funds for the Central Non-profit Research Institution of CAF (CAFYBB2017ZX001-2).

\section{References}

Amateis, R.L., Burkhart, H.E. 2012. Rotation-age results from a loblolly pine spacing trial. - Southern Journal of Applied Forestry, 36(1), 11-18.

Arisman, H., Kurinobu, S., Hardiyanto, E. 2005. A simple step-wise procedure for predicting stand development of Acacia mangium plantations based on the maximum size-density line in South Sumatra, Indonesia. - Journal of Forest Research, 10(4), 313-318.

Arisman, H., Kurinobu, S., Hardiyanto, E. 2004. Minimum distance boundary method, maximum sizedensity lines for unthinned Acacia mangium plantations in South Sumatra, Indonesia. - Journal of Forest Research, 9(3), 233-237. 
Beekhuis, J. 1965. Crown depth of radiata pine in relation to stand density and height. - New Zealand Journal of Forestry, 10(1), 43-61.

Brunet-Navarro, P., Sterck, F.J., Vayreda, J., MartinezVilalta, J., Mohern, G.M.J. 2016. Self-thinning in four pine species, an evaluation of potential climate impacts. - Annals of Forest Science, 73, 1025-1034.

Burkhart, H.E. 2013. Comparison of maximum sizedensity relationship based on alternate stand attributes for predicting tree numbers and stand growth. - Forest Ecology and Management, 289, 404-408.

Burkhart, H.E., Tomé, M. 2012. Quantifying stand density. - Modeling Forest Trees and Stands. Springer, Dordrecht, 175-200.

Charru, M., Seynave, I., Morneau, F., Rivoire, M., Bontemps, J.D. 2012. Significant differences and curvilinearity in the self-thinning relationships of 11 temperate tree species assessed from forest inventory data. - Annals of Forest Science, 69(2), 195-205.

Cheng, X., Kiyoshi, U., Tsuyoshi, H., Shao, P. 2011. Height growth, diameter-height relationships and branching architecture of Pinus massoniana and Cunninghamia lanceolata in early regeneration stages in Anhui Province, eastern China, effects of light intensity and regeneration mode. - Forestry Studies in China, 13(1), 1-12.

Cui, L., Zhang, X., Duan, A., Zhang, J. 2016. A hierarchical bayesian model to predict maximum-size density line for Chinese fir plantation in Southern China. - Scientia Silvae Sinicae, 52(9), 95-102.

Curtis, R.O. 2010. Effect of diameter limits and stand structure on relative density indices, a case study. - Western Journal of Applied Forestry, 25(4), 169-175.

Daniels, R.F., Burkhart, H.E. 1988. An integrated system of forest stand models. - Forest Ecology and Management, 23(2-3), 159-177.

Das, S., Singh, T.P. 2016. Forest type, diversity and biomass estimation in tropical forests of Western Ghat of Maharashtra using geospatial techniques. - Small-Scale Forestry, 15(4), 517-532.

Dehane, B., Hernando, C., Guijarro, M., Madrigal, J. 2017. Flammability of some companion species in cork oak (Quercus suber L.) forests. - Annals of Forest Science, 74, 60.

Dong, T., Zhang, Y., Zhang, Y., Zhang, S. 2016. Continuous planting under a high density enhances the competition for nutrients among young Cunninghamia lanceolata saplings. - Annals of Forest Science, 73(2), 331-339.

Durham, D.F. 1991. Notes on "Carrying Capacity". Population Environment, 13(2), 119-120.

Gu, H., Yang, K., Li, C., Yang, F. 2001. Establishment of standardized site index of needle-leaved forest and its application in evaluation of site quality in Daxing'an mountains. - Journal of Forestry Research, 12(2), 128-132.
Harms, W.R., DeBell, D.S., Whitesell, C.D. 1994. Stand and tree characteristics and stockability in Pinus taeda plantations in Hawaii and South Carolina. Canadian Journal of Forest Research, 24(3), 511521.

Hui, G., Zhang, L., Hu, Y., Wang, H., Zhang, G. 2016. Stand crowding degree and its application. - Journal of Beijing Forestry University, 38(10), 1-6. (In Chinese with English abstract).

Inoue, A. 2009. Allometric model of the maximum size-density relationship between stem surface area and stand density. - Journal of Forest Research, 14(5), 269-275.

Inoue, A., Miyake, M., Nishizono, T. 2004. Allometric model of the Reineke equation for Japanese cypress (Chamaecyparis obtusa) and red pine (Pinus densiflora) stands. - Journal of Forest Research, 9(4), 319-324.

Kurinobu, S., Miyaura, T. 2011. A simultaneous estimation procedure for the parameters of the maximum size-density line and self-thinning curve to predict stand development of fast-growing tropical species. - Journal of forestry Research, 16(6), 522-525.

Ma, L. 2015. Visual simulation research on the effect of crown on the tree growth for Cunninghamia Lanceolata. Beijing, Chinese Academy of Forestry, 60 pp. (In Chinese with English abstract).

Ma, L., Zhang, H., Li, Y., Guo, M., Zhang, Y. 2015. Growth simulation of Chinese fir based on individual-tree process model. - Forest Research, 28(4), 551-554 (In Chinese with English abstract).

Meng, X. 1996. Forest mensuration ( $2^{\text {nd }}$ edition). Beijing, China Forestry Publishing House, 17-23. (In Chinese).

Mitsuda, Y., Yoshida, S., Imada, M. 2003. Development of height curves for Japanese larch in relation to gis-derived site index. - Journal of Forest Research, 8(3), 199-207.

Nagaike, T., Kubota, Y., Watanabe, N. 1999. The effects of selective logging on stand structure and the regeneration of subboreal forests in Hokkaido, northern Japan. - Journal of Forest Research, 4(1), 41-45.

Nilson, A. 2006. Modeling dependence between the number of trees and mean tree diameter of stand, stand density and stand sparsity. - Cieszewski, C.J, Strub. M. (eds). Second International Conference on Forest Measurement and Quantitative Methods and Management \& the 2004 Southern Mensurationists Meeting 15-18 June 2004 Hot Springs, Arkansas, USA. University of Georgia, Athens, USA, 74-94.

Nutto, L., Spathelf, P., Seling, I. 2007. Management of individual tree diameter growth and implications for pruning for Brazilian Eucalyptus grandis Hill ex Maiden. - Floresta, 36(3), 351-368.

Peng, C., Wen, X. 2006. Forest simulation models. Shao, G., Reynolds, K.M. (eds). Computer Applications in Sustainable Forest Management. Springer, Dordrecht, 101-125. 
Pinheiro, J., Bates, D., DebRoy, S., Sarkar, D., R Core Team. 2017. nlme: Linear and nonlinear mixed effects models. R package version 3, 1-131.

Qiu, S., Xu, M., Li, R., Zheng, Y., Clark, D., Cui, X., Liu, L., Lai, C., Zhang, W., Liu, B. 2015. Climatic information improves statistical individual-tree mortality models for three key species of Sichuan province, China. - Annals of Forest Science, 72(4), 443-455.

Ramananantoandro, T., Ramanakoto, M.F., Rajoelison, G.L., Randriamboavonjy, J.C., Rafidimanantsoa, H.P. 2016. Influence of tree species, tree diameter and soil types on wood density and its radial variation in a mid-altitude rainforest in Madagascar. - Annals of Forest Science, 73(4), 1113-1124.

Reineke, L.H. 1933. Perfecting a stand-density index for even-aged forests. - Journal of Agricultural Research, 46(7), 627-638.

Sun, H., Zhang, J., Duan, A. 2014. Study on the selfpruning of Chinese fir plantation. - Forest Research, 27(5), 626-630. (In Chinese with English abstract).

Sun, H., Zhang, J., Duan, A., He, C. 2007. A review of stand basal area growth models. - Forestry Studies in China, 9(1), 85-94.

Sun, Y., Li, S., Cui, H., Li, C., Liu, P., Zhang, J. 1999. Growth models and site index table of natural Korean pine forests. - Journal of Forestry Research, 10(4), 236-238.

Xiang, C., Zhang, J., Duan, A., Zhang, X. 2015. Effects of site quality and planting density on wood assortment rate in Chinese fir plantation. - Forest Research, 28(5), 654-659. (In Chinese with English abstract).
Xue, L., Hou, X., Li, Q., Hao, Y. 2015. Self-thinning lines and allometric relation in Chinese fir (Cunninghamia lanceolata) stands. - Journal of Forestry Research, 26(2), 281-290.

Yang, S.I., Burkhart, H.E. 2017. Estimation of carrying capacity in Loblolly pine (Pinus taeda L.). - Forest Ecology and Management, 385, 167-176.

Zeide, B. 2010. Comparison of self-thinning models: an exercise in reasoning. - Trees, 24(6), 1117-1126.

Zhang, L., Hui, G., Sun, C. 2011a. Comparison of different stand density measures. - Journal of Fujian College of Forestry, 31(3), 257-261. (In Chinese with English abstract).

Zhang, L., Hui, G., Sun, C. 2011b. The first thinning age of Pinus massoniana plantation. - Journal of Central South University of Forestry \& Technology, 31(6), 22-27. (In Chinese with English abstract).

Zhang, W., Jia, X., Bai, Y., Wang, G. 2011. The difference between above- and below-ground selfthinning lines in forest communities. - Ecological Research, 26(4), 819-825.

Zhang, X., Duan, A., Zhang, J. 2013. Tree biomass estimation of Chinese fir (Cunninghamia lanceolata) based on Bayesian method. - PLoS One, 8(11), e79868.

Zhang, J., Hao, Z., Sun, I., Song, B., Ye, J., Li, B., Wang, X. 2009. Density dependence on tree survival in an old-growth temperate forest in northeastern China. - Annals of Forest Science, 66(2), 204-204.

Zhao, L., Li, C., Tang, S. 2013. Individual-tree diameter growth model for fir plantations based on multilevel linear mixed effects models across southeast China. - Journal of Forest Research, 18(4), 305-315. 